\title{
El lugar de Amauta en la genealogía de la perspectiva de análisis de la descolonialidad del saber
}

César GERMANÁ

\begin{abstract}
RESUMEN
El proyecto intelectual y político de Amauta implicaba el cuestionamiento a la perspectiva eurocéntrica de conocimiento en las ciencias y en las humanidades dominante en la década de 1920 debido a la hegemonía del pensamiento de la "generación del novecientos". Amauta buscaba expresar el nuevo espíritu que surgía en la "nueva generación" de intelectuales y artistas que tenía como tarea común "su voluntad de crear un Perú nuevo dentro del mundo nuevo". La realización de este objetivo comportaba una nueva manera de plantear y conocer los problemas peruanos cuyo eje central estaba dado por una perspectiva de análisis donde se articulaba el logos y el mito que para el eurocentrismo constituían paradigmas antagónicos. En la presente ponencia se exploran algunas de las orientaciones epistemológicas de Amauta que apuntan de manera todavía embrionaria, pero significativa y consistente a la perspectiva de la descolonialidad del saber.
\end{abstract}

PALABRAS CLAVE: con la vialidad del poder, Amauta, Mariátegui, eurocentrismo, epistemología.

\section{Amauta place in the genealogy from the perspective of analysis of the decolonization of knowledge}

\section{ABSTRACT}

The intellectual and political project of the Amauta magazine question the Eurocentric perspective of knowledge in the sciences and the humanities during the 1920s due to the hegemony of thought of the "generation of the twentieth century". Amauta sought to express the new spirit that arose in the "new generation" of intellectuals and artists who had a common task: "their willingness to create a new Peru in the new world". This aim involved a new way of posing problems and to understand the peruvian issues whose central axis was an analytical perspective which has been dividing the logos and the myth, the eurocentrism. In this paper explores some of the epistemological orientations that point out Amauta, still in an embryonic way, but significantly and consistently toward the perspective of the coloniality of knowledge

KEYWORDS: coloniality of knowledge, Amauta, Mariategui, Eurocentric, epistemology. 
E I proyecto intelectual y político de Amauta implicaba el cuestionamiento a la perspectiva eurocéntrica de conocimiento en las ciencias y en las humanidades dominante en la década de 1920 debido a la hegemonía del pensamiento de la "generación del novecientos". Amauta buscaba expresar el nuevo espíritu que surgía en la "nueva generación" de intelectuales y artistas que tenía como tarea común "su voluntad de crear un Perú nuevo dentro del mundo nuevo". La realización de este objetivo comportaba una nueva manera de plantear y conocer los problemas peruanos cuyo eje central estaba dado por una perspectiva de análisis donde se articulaba el logos y el mito que para el eurocentrismo constituían paradigmas antagónicos. En la presente ponencia se exploran algunas de las orientaciones epistemológicas de Amauta que apuntan de manera todavía embrionaria, pero significativa y consistente- a la perspectiva de la descolonialidad del saber.

Una de las variantes más productivas de la nueva ciencia social que ha surgido en América latina en las últimas décadas es la perspectiva de análisis de la colonialidad/ descolonialidad del poder que busca superar el eurocentismo - orientación epistemológica con la se construyeron históricamente las ciencias sociales en el siglo XIX- sin caer en el escepticismo relativista, y que ha producido un pensamiento notablemente original y rico en la elaboración de conocimientos y cuestiones de investigación sobre la sociedad latinoamericana, en tanto parte del sistema-mundo moderno/colonial. Esta perspectiva ha logrado desarrollar una autonomía intelectual que le ha permitido superar las alternativas eurocéntricas en el estudio de la sociedad y de su transformación y nos permite establecer las bases de una "epistemología otra"; esto es, un enfoque del conocimiento social que no se sitúa en el ámbito de la modernidad eurocéntrica sino que trata de lo que Walter Mignolo ha denominado un "pensamiento fronterizo".

El concepto central en este enfoque es el de colonialidad del poder propuesto por Aníbal Quijano'. Para Quijano, con la conquista ibérica del continente que posteriormente se va a llamar América, se constituyó un nuevo patrón de poder que era efectivamente mundial y que duraría más de cinco siglos. Este patrón de poder mundial tiene como fundamento la colonialidad y la modernidad.

Modernidad y colonialidad aparecen como las dos caras del patrón mundial de poder que ha dominado el planeta en los últimos quinientos años y que actualmente

1 Aníbal Quijano introdujo el concepto de colonialidad del poder en Quijano (1991b). Posteriormente lo desarrolló en varios otros textos: Quijano y Wallerstein (1992), Quijano (1993, 2000a, 2000b, 2000c, 2001, 2003, 2004, 2007, 2009 y 2010). Para un debate sobre este concepto, véanse los siguientes textos: Mignolo (2003), Escobar (2003) y Pachón Soto (2007).

\section{0/ REVISTA DE SOCOLLOGíA 26}


ha llegado a un punto de bifurcación, abriéndose un período de crisis estructural. La modernidad se presenta como la cara ilustrada de este patrón de poder y se le puede considerar como el proceso de una creciente racionalización instrumental de los diferentes órdenes de la vida social. En ese sentido, expresaría lo nuevo y lo más avanzado de la especie; y donde la historia humana sería considerada como una trayectoria cuyo destino final estaría dado por la Europa Occidental que surge en el siglo XVl; proceso que constituiría el fin de la historia. La otra cara, la menos reluciente y que normalmente se oculta, es la colonialidad; esto es, las relaciones de poder que se establecen entre lo europeo y lo no europeo sobre la base de la "raza", noción que es presentada como supuestas diferencias biológicas entre los seres humanos que hacen a unos superiores - los conquistadores - y otros inferiores -los colonizados; la colonialidad ha producido una alquimia social: la transmutación de las condiciones de dominación —un hecho social—, en jerarquías biológicas; esto es, en relaciones raciales. Más aún, y este es el efecto más perverso de esas relaciones coloniales de dominación, los propios dominados se convierten en cómplices de su propia dominación al aceptar como legítima la supuesta superioridad biológica de los conquistadores. Lo que fue producto de la dominación colonial, se ha mantenido como colonialidad cuando las áreas colonizadas logran su autonomía jurídico-política; reproduciéndose las relaciones "raciales" de superioridad/inferioridad como la base sobre la que se sostienen las actuales estructuras del patrón de poder mundial. La colonialidad del poder ha sido la forma de dominación más eficiente tanto en los aspectos materiales como intersubjetivos de la existencia social. En este caso se trata de la colonialidad del saber; esto es, la hegemonía del eurocentrismo que ha impuesto la racionalidad instrumental en el mundo entero como la única forma legítima de racionalidad, excluyendo y marginando las formas de producir conocimientos y los imaginarios de los pueblos que fueron colonizados.

\section{$\| I^{2}$}

Uno de los más importantes pensadores, en la periferia del sistema-mundo moderno/ colonial, que desarrolló fructíferas propuestas que constituyen una de las raíces de la manera de producir conocimiento orientado a la descolonialidad del poder y del saber fue José Carlos Mariátegui (1894-1930). En Mariátegui encontramos uno de los hitos fundamentales que ha permitido avanzar en la construcción de un pensamiento social alternativo al del eurocentrismo del patrón de poder moderno/colonial. Quizás

2 Esta sección retoma con algunas modificaciones varios textos de mi ensayo "El campo intelectual peruano de la década de los años veinte y el proyecto creador de Amauta", ponencia presentada en el Seminario Internacional Amauta y su época. 
el hecho de encontrarse en la exterioridad colonial y proponerse la descolonización como condición principal para pensar una sociedad diferente, le permitió percibir con bastante claridad la naturaleza de la estructura de poder que dominaba el mundo y, en particular, su carácter colonial. Se trata de un pensamiento minoritario, marginal a las corrientes intelectuales dominantes en su época, fragmentario e inacabado y libre - en lo fundamental — de toda forma de etnocentrismo. Lo característico de la perspectiva teórica de José Carlos Mariátegui se encuentra en su manera de abordar la realidad histórico-social. Sin duda, ha sido Aníbal Quijano quien ha señalado con claridad la originalidad del pensamiento de José Carlos Mariátegui cuando define su perspectiva epistemológica como "un modo de pensar, de indagar y de conocer, que se constituye por la unidad tensional entre dos paradigmas que la cultura dominante - la manera eurocéntrica de la modernidad - desune y opone como inconciliables: el logos y el mito" (Quijano, 1991a: IX). Esta perspectiva le permitió a Mariátegui evitar los escollos tanto del positivismo como del racionalismo y comprender ese proceso creador que para él era el socialismo.

La revista Amauta fue el campo intelectual experimental donde se comenzaron a cristalizar las diversas propuestas de análisis para "plantear, esclarecer y conocer los problemas peruanos desde puntos de vista doctrinarios y científicos. Pero consideraremos siempre al Perú dentro del panorama del mundo", como señala la Presentación del $\mathrm{N}^{\circ} 1$ de Amauta. Se trataba de una experiencia innovadora de un diálogo de saberes, en donde la cultura occidental se ponía en un nivel de igualdad con respecto a las tradiciones de los pueblos originarios, lo que es significativamente expresado en el título de la revista al que se considera un "homenaje al Incaismo". En el editorial "Aniversario y balance" del número 17 de Amauta (setiembre de 1928) Mariátegui precisará el sentido de este homenaje:"Amauta no debería ser un plagio, ni una traducción. Tomábamos una palabra inkaica, para crearla de nuevo. Para que el Perú indio, la América indígena, sintiera que esta revista era suya".

La singularidad de la propuesta José Carlos Mariátegui solo puede ser comprendida si se tiene en cuenta que el conjunto de su obra fue el resultado del encuentro de una doble herencia: por un lado, la cultura occidental, en particular el marxismo que desempeñó un papel central en la constitución de sus puntos de vista teóricos y políticos; y de otro, la cultura andina, verdadero substrato de sus reflexiones y de sus orientaciones vitales. Precisamente, fue en el encuentro de estas dos tradiciones culturales donde se constituyó la matriz básica de su pensamiento. Y solamente a partir de allí es posible comprender el triple debate que estableció con las corrientes políticas e ideológicas más importantes de su época: la "generación del 900 ", intelectuales representativos de la cultura criollo-oligárquica, el nacionalismo democrático radical de Haya de la Torre y el marxismo-leninismo de la Tercera Internacional. El resultado 
de esas polémicas le permitió arribar a una concepción original del socialismo que denominó "socialismo indoamericano".

En el contexto histórico que se editó Amauta —la década de 1920-, empezaban a difundirse ideas, imágenes del mundo y motivaciones, cuestionando los sistemas de legitimación y de moralidad sobre los que se asentaba el orden oligárquico. Estos impulsos hacia el cambio del mundo intersubjetivo surgieron primero entre los intelectuales, y posteriormente, se propagaron entre las capas medias urbanas y entre los obreros. Aunque este complejo proceso no ha sido estudiado de manera sistemática, se han señalado por lo menos dos núcleos de problemas que habrían influido en esos cambios de mentalidad: primero, la derrota del Perú en la "guerra del Pacífico" y la creciente presencia del capital imperialista en la economía peruana; segundo, las insurrecciones indígenas y las luchas obreras en las dos primeras décadas del siglo XX. Lo primero porque puso en evidencia la debilidad del país como nación y la necesidad de reconstruirla sobre nuevas y más sólidas bases; así fue emergiendo una conciencia nacional. Lo segundo porque mostró la marginación de las masas indígenas y de los obreros y la necesidad de que alcanzaran su efectiva emancipación; así fue emergiendo una conciencia social.

Inspirados - al igual que Manuel González Prada - en la filosofía positivista surge, a principios del siglo XX, un grupo de escritores a los que se les va a conocer como "generación del novecientos". Estos escritores se consideraban como una minoría selecta capaz de influir intelectualmente sobre la clase dominante — de la que socialmente procedían y a la que querían reformar - para que ésta modernizara la sociedad peruana según el modelo de la modernidad europea. Para ello, proponían una reforma de las instituciones políticas y educativas, pues consideraban que de individuos mejor instruidos surgiría una aristocracia del espíritu, sustento de una verdadera democracia. Si bien la "generación del 900" no logró la materialización de su proyecto de reformas, en cambio sus ideas se convirtieron en el punto de referencia de la cultura peruana de los primeros decenios del siglo XX.

Hacia 1920, el proceso de reforma intelectual y moral de la sociedad peruana siguió una vía diferente de la trazada por la "generación de 900". En efecto, en ese período emerge un grupo de escritores guiados por un espíritu de renovación en el pensamiento, el arte y la literatura. Tenía como antecedente la generación radical de Manuel González Prada y el iconoclasta grupo de escritores reunidos alrededor de la revista Colónida. Mariátegui los designaba como la "nueva generación" y los consideraba un movimiento animado por un espíritu de cambio. Convergían en él dispares corrientes ideológicas pero todas animadas de un común objetivo: la "voluntad de crear un Perú nuevo dentro del mundo nuevo". Un momento clave en la cristalización de ese corriente fue la creación por Víctor Raúl Haya de la Torre, 
en México, de la Alianza Popular Revolucionaria Americana (APRA), en el año 1924. Surgía como un frente político con el declarado propósito de agrupar a todos las corrientes antioligárquicas del Perú y de Latinoamérica: nacionalistas, indigenistas, socialistas. Sin embargo, en el curso del año 1928, ese movimiento se fue diferenciando política e ideológicamente para, finalmente, desembocar en una ruptura abierta. En "Aniversario y balance", editorial del número 17 de Amauta, Mariátegui señala con claridad como en los dos años de existencia de Amauta había sido "una revista de definición ideológica"; sin embargo, consideraba ese "trabajo de definición ideológica" había concluido. Dos fueron las tendencias principales alrededor de las cuales se reagrupó la „nueva generación“: el nacionalismo democrático radical y el socialismo revolucionario.

La“nueva generación" estuvo formada por escritores, historiadores, economistas y artistas que surgieron en la vida cultural y política del Perú después de la Primera Guerra Mundial. Todos ellos tenían en común la preocupación por la "realidad profunda del Perú" y un "espíritu de renovación". Este esfuerzo por comprender el Perú en los años veinte cobra mayor importancia si se tiene en cuenta el nivel incipiente de los estudios histórico-sociales en el país de esa época. A partir de ese momento se empieza a investigar las diversas áreas de la realidad peruana: la historia, la economía, la estructura social.

Precisamente, éste fue el mérito mayor que Mariátegui encontraba en los hombres de su generación, la "nueva generación". "En el haber de nuestra generación —escribió en el artículo "Hacia el estudio de los problemas peruanos" — se puede y debe ya anotar una virtud y un mérito: su creciente interés por el conocimiento de las cosas peruanas" (Mariátegui, 1994, t. I: 299). Esta nueva actitud de la intelligentsia peruana, Mariátegui la veía como el resultado de las profundas modificaciones que se estaban produciendo en el mundo y también en la sociedad peruana. Sobre las causas que motivaron la extensa ola de agitación que atravesó a toda América Latina en el período de la posguerra, Mariátegui escribió en los 7 ensayos de interpretación de la realidad peruana:

De igual modo, este movimiento se presenta íntimamente conectado con la recia marejada postbélica. Las esperanzas mesiánicas; los sentimientos revolucionarios, las pasiones místicas propias de la postguerra, repercutían particularmente en la juventud universitaria de Latinoamérica. El concepto difuso y urgente de que el mundo entraba en un ciclo nuevo, despertaba en los jóvenes la ambición de cumplir una función heroica y de realizar una obra histórica. Y, como es natural, en la constatación de todos los vicios y fallas del régimen económico social vigente, la voluntad y el anhelo de renovación encontraban poderosos estímulos. La crisis mundial invitaba a los pueblos latinoamericanos, con insó-

\section{4/ REVUSTA DE SOCOLLOGíA 26}


lito apremio, a revisar y resolver sus problemas de organización y crecimiento. Lógicamente, la nueva generación sentía estos problemas con una intensidad y un apasionamiento que las anteriores generaciones no habían conocido. (Mariátegui, 1994, t. I: 55-56).

De esta voluntad de renovación que se había apoderado de los "hombres nuevos", Mariátegui deducía el nacimiento de "una urgente y difusa aspiración a entender la realidad peruana". Esta necesidad de estudiar los problemas peruanos se hacía más apremiante debido a los cambios que se comenzaban a operar en el país. En el período de la postguerra se acentúa la presencia del imperialismo norteamericano, aparece un movimiento obrero y un movimiento campesino y se manifiesta el descontento de las capas medias. Todo ello se traduciría en la creciente erosión del sistema oligárquico de poder. La dictadura del presidente Leguía (1919-1930), cristalizó todas las tendencias y contradicciones de un país en proceso de transformación. Los intelectuales de esa convulsionada época buscaron definir su propia identidad. No podía ser ya la "latinidad" de la "generación del novecientos". La crisis de la civilización occidental era demasiado evidente para encontrar en ella el modelo del futuro del Perú. La salida la buscaron en la propia realidad peruana. Pero esa realidad no podían encontrarla en los intelectuales de las generaciones anteriores — "sumisa clientela" de la clase dominante- pues "los intereses de esta casta les impedía descender de su desdeñoso y frívolo Parnaso a la realidad profunda del Perú". La "exploración y definición de la realidad profunda del Perú" correspondía a la nueva generación. Esta idea central del artículo "Un programa de estudios sociales y económicos", Mariátegui la resumió en el siguiente párrafo:

La nueva generación quiere ser idealista. Pero, sobre todo, quiere ser realista. Está muy distante, por tanto, de un nacionalismo declamatorio y retórico. Siente y piensa que no basta hablar de peruanidad. Que hay que comenzar por estudiar y definir la realidad peruana. Y que hay que buscar la realidad profunda: no la realidad superficial (Mariátegui, 1994, t. I: 301).

Para Mariátegui esa "realidad profunda" era el mundo indígena. En él encontraba el fundamento del Perú. Como el Perú se había construido"sin el indio y contra el indio" era una nación incompleta, "en formación". Por eso, propugnaba "la reconstrucción peruana sobre la base del indio" como la tarea de los que querían cambiar la sociedad peruana. 
En Amauta podemos encontrar artículos y ensayos que muestran, desde diferentes puntos de vista, algunos de los aspectos fundamentales del proceso por el cual se va a ir constituyendo nuevas vías para establecer formas de conocimiento para encontrar la "realidad profunda" del país. Entre otros, podemos destacar dos elementos de esta perspectiva cognoscitiva que me parecen fundamentales.

En primer lugar, el papel que José Carlos Mariátegui le asigna a la imaginación en la producción del conocimiento. De allí que la revista publicara una gran variedad de textos de poesía, cuentos y fragmentos de novelas, así como ensayos de crítica literaria, de pintura, escultura, arquitectura y cinema de los más importantes escritores peruanos y latinoamericanos. Para Mariátegui era fundamental la "imaginación creadora" en el conocimiento de la realidad histórico-social como lo muestra el artículo "Veinticinco años de sucesos extranjeros":

Se ha reivindicado, contra la chata ortodoxia realista, los fueros de la imaginación creadora, lo que ha traído ventajas asombrosas para el descubrimiento de la realidad. Pues con los derechos de la fantasía, y la fantasía, se ha averiguado sus fines, que es como decir sus límites (Mariátegui, 1994, t. I: 1218).

En la presentación del №3 de Amauta, "Arte, revolución y decadencia”, Mariátegui señala que el arte se nutre "del absoluto de su época". Por esta razón encuentra que el arte nuevo y arte burgués corresponden a la presencia de las dos almas que coexisten en el mundo contemporáneo: la de la revolución y la de la decadencia. "La decadencia de la civilización capitalista se refleja en la atomización, en la disolución de su arte". Pero también percibía en la crisis de la sociedad burguesa el surgimiento del arte nuevo: "Es la transición del tramonto al alba. En esta crisis se elaboran dispersamente los elementos del arte del porvenir".

Así pues, encontramos el rechazo al racionalismo y al cientificismo. Para Mariátegui el conocimiento no se limitaba a los resultados de la ciencia. Había en la realidad histórico-social multitud de fenómenos que escapaban a los métodos racionales. Por eso, hablaba de la "bancarrota del positivismo y del cientificismo", pero no de la ciencia, pues veía en ella la posibilidad de lograr la explicación de determinados aspectos de la realidad. Sin embargo, para que ésta sirviera a la tarea de transformar la realidad social tenía que ser completada con otras formas de conocer como el caso de la imaginación creadora. En el ensayo "El hombre y el mito" Mariátegui escribe: 
Los filósofos nos aportan una verdad análoga a la de los poetas. La filosofía contemporánea ha barrido el mediocre edificio positivista. Ha esclarecido y demarcado los modestos confines de la razón. Y ha formulado las actuales teorías del Mito y de la Acción. Inútil es, según estas teorías, buscar una verdad absoluta. La verdad de hoy no será la verdad de mañana. Una verdad es válida solo para una época. Contentémonos con una verdad relativa (Mariátegui, 1994, t. I: 498).

Este fue precisamente el aspecto que Mariátegui más admiraba en la literatura surrealista. Percibía en ella la revalorización del rol de la fantasía y de la ficción como medios para abordar la realidad social, para captar "su esencia viviente". Al ir más allá de lo inmediato, se podrían aprehender más aspectos de la realidad de los que captaría quien únicamente se propusiese reproducirla. "Y la experiencia ha demostrado escribió en un ensayo sobre Philippe Soupault que con el vuelo de la fantasía es como mejor se puede abarcar todas las profundidades de la realidad. No, por supuesto, falsificándola o inventándola. La fantasía no surge de la nada. Y no tiene valor sino cuando crea algo real" (Mariátegui, t. I: 676).

Mariátegui se interesó por los aspectos no racionales de la vida humana. Por ello subrayó la importancia del psicoanálisis y de la sociología de Pareto ${ }^{3}$. Pero la mejor muestra de cómo intentaba comprender la vida social con instrumentos en los que intervenía la imaginación, se encuentra en una narración corta La novela y la vida. Siegfried y el profesor Canella (Mariátegui, 1994, t. I: 1361-1374). José Carlos Mariátegui la definió en la carta a S. Glusberg del 18 de febrero de 1930 como un"relato, mezcla de cuento y crónica, de ficción y realidad" (Mariátegui, 1994, t. I: 2076). Y este relato puede ser considerado como un intento de ir más allá de lo inmediato para captar lo real por medio de la ficción. De esta manera, el Amauta llega a esta paradójica afirmación: “La vida excede la novela; la realidad a la ficción" (Mariátegui, 1994, t. I: 1361).

El otro aspecto de la perspectiva epistemológica que atraviesa a Amauta es la búsqueda por establecer la especificidad de la formación social peruana. El problema del indio se convierte en una preocupación de Amauta. Los artículos publicados en la sección El proceso del gamonalismo y en los diferentes números de la revista, incluyendo los del propio José Carlos Mariátegui, dan cuenta del interés por el debate de esta problemática central para comprender la singularidad de la sociedad peruana.

3 J. C. Mariátegui valoró el psicoanálisis como una de las teorías modernas que podían completar el marxismo. Véase la siguiente afirmación: "Freudismo y marxismo, aunque los discípulos de Freud y de Marx no sean todavía los más propensos a entenderlo y advertirlo, se emparentan, en sus distintos dominios, no sólo por lo que en sus teorías había de "humillación", como dice Freud, para las concepciones idealistas de la humanidad sino por su método frente a los problemas que abordan" (Mariátegui, 1994, t. I: 1311). Pareto no solo era para Mariátegui el inspirador de la teoría soreliana de los "mitos"(Mariátegui, 1994, t. I: 1300), sino que, con su teoría de los "residuos"y"derivaciones" propuesta en su Tratado de Sociología, le permite comprender la supervivencia de las tradiciones andinas. Sobre este último tema véase los 7 ensayos de interpretación de la realidad peruana (1994, t. I: 153-154) 
Un libro fundamental en la evolución intelectual de Mariátegui que lo incentivó en su búsqueda del mundo andino fue La decadencia de Occidente (1918 / 1923) de Oswald Spengler. De este libro José Carlos Mariátegui escribió en el artículo “La urbe y el campo" que no se le "puede hoy olvidar en ningún intento de interpretación de la historia" (Mariátegui, 1994, t. I:510) ${ }^{4}$.Y. Moretic, un crítico perspicaz de las ideas estéticas del Amauta, cree ver el "daño causado por las ideas de Spengler en el pensamiento de Mariátegui"; sin embargo, si se analiza con más cuidado la obra del autor de los 7 ensayos se puede constatar que las ideas del escritor alemán funcionaron más bien como un revelador, en la conciencia del Amauta, de la situación de crisis de la civilización capitalista y de la necesidad de buscar fuera de Europa un nuevo sentido de la vida. Jean Franco, en su estudio sobre la cultura hispanoamericana del siglo XX, ha reparado en la influencia de las ideas de Spengler en los escritores latinoamericanos del período de la posguerra. Sostiene que las tesis de La decadencia de Occidente sugerían la posibilidad de que "las culturas indígenas americanas podían igualar y aún superar a la cultura europea y que, por consiguiente, no había razón para que no pudiera desarrollarse en el Nuevo Mundo una civilización más avanzada que la europea"s.

Esa búsqueda en las tradiciones de los pueblos originarios llevó a José Carlos Mariátegui a sostener la original tesis del socialismo indo-americano que implicaba un nuevo imaginario social y que se entroncaba con las tradiciones milenarias de los pueblos originarios de América. "El pasado incaico —escribió en el artículo "La tradición nacional" — ha entrado en nuestra historia, reivindicado no por los tradicionalistas sino por los revolucionarios. En esto consiste la derrota del colonialismo, sobreviviente aún, en parte, como estado social [...]. La revolución ha reivindicado nuestra más antigua tradición" (Mariátegui, t. I: 326).

Ciertamente, Mariátegui no buscaba volver al pasado precolonial; aspiraba, más bien, a hallar las raíces indígenas del futuro como escribe en "Aniversario y balance":

El socialismo, en fin, está en la tradición americana. La más avanzada organización comunista primitiva, que registra la historia, es la inkaica. No queremos ciertamente, que el socialismo en América sea calco y copia. Debe ser creación heroica. Tenemos que dar vida, con nuestra propia realidad, en nuestro propio lenguaje, al socialismo indo-americano. He aquí una misión digna de una generación nueva .

4 En un artículo publicado en 1922,“El crepúsculo de la civilización”, Mariátegui utiliza la teoría de Spengler "uno de los pensadores más originales y sólidos de la Alemania actual" para proclamar que"política y económicamente, la sociedad europea ofrece el espectáculo de una sociedad en decadencia" (Mariátegui, 1994, t. I: 597)

5 Jean Franco, La cultura moderna en América Latina, México, Joaquín Mortiz, 1971, pp. 116-117. El siguiente comentario en la p. 79 (nota) define bien la importancia de Spengler en América Latina durante ese período: "La célebre obra de Spengler comenzó a aparecer en 1918. Fue ampliamente discutida en toda Latinoamérica en los veinte, y las referencias a ella son muy frecuentes en los ensayos de la época. Desafortunadamente no existe un estudio sobre el efecto de las ideas spenglerianas en la América Latina". 
Para comprender la realidad histórico-social desde esta perspectiva, Mariátegui tuvo que seguir el ejemplo de Marx: encontrar su método en la entrañas de la historia del Perú. Por ello, si utilizó determinadas categorías del marxismo europeo y de otras corrientes filosóficas no marxistas, las redefinió de acuerdo a sus necesidades teóricas y prácticas con el objeto de comprender y de transformar la realidad peruana. Esta idea ha sido planteada por A. Quijano con precisión, en relación a la singularidad de José Carlos Mariátegui en el debate dentro del movimiento socialista de los años veinte:

Y lo que identifica esa singularidad, vista desde el mundo de hoy, es el empleo de categorías elaboradas en la visión eurocéntrica de la racionalidad moderna, pero redefinidas por su inserción dentro de una perspectiva de conocimiento radicalmente distinta de la que dominaba, entonces, entre los marxistas europeos y, sobre todo, en el estalinismo internacional (Quijano, 1991a: XI).

En los análisis del funcionamiento de la sociedad peruana y de sus tendencias de cambio, Mariátegui elaboró un conjunto de categorías con las que buscó expresar los fenómenos específicos de esta realidad. No trasladó simplemente esos conceptos de la realidad europea a la sociedad peruana. De alguna manera, los reelaboró con el objeto de que expresaran los fenómenos nuevos que su investigación le revelaba. En este sentido, su investigación de la realidad peruana le fue ofreciendo el método y la teoría necesarios para entender su modo de organización y de transformación. El autor de los 7 ensayos de interpretación de la realidad peruana concebía las tendencias principales que regían la sociedad peruana y cómo en ellas encontraba la lógica del socialismo.

\section{Referencias bibliográficas}

EsCOBAR, Arturo (2003)."Mundos y conocimientos de otro modo. El programa de investigación de modernidad/colonialidad latinoamericano", en: Tabula Rasa, No. 1, Bogotá, pp. 51-86. MARIÁTEGUI, José Carlos (1994). Mariátegui total, Lima, Editora Amauta, 2 t.

MıGNolo, Walter (2003). Historias locales/diseños globales. Colonialidad, conocimientos subalternos y pensamiento fronterizo. Madrid: Akal.

PACHÓN SOTO, Damián (2007). "Nueva perspectiva filosófica en América Latina: el grupo Modernidad/Colonialidad", en Peripecias, $N^{\circ} 63$.

QUIJANO, Aníbal e Immanuel WalleRSTEIn (1992). “Americanity as a Concept or the Americas in the Modern World-System", en: International Journal of Social Sciences, No. 134, UNESCO, noviembre, pp. 617-627.

QuiJano, Aníbal (1991a). “Prólogo” a: José Carlos Mariátegui, Textos básicos. Lima: Fondo de Cultura Económica. 
QuIJANO, Aníbal (1991b). “Colonialidad y modernidad/racionalidad”, en: Revista del Instituto Indigenista Peruano, Vol. 13, No. 29, Lima, pp. 11-20.

QUIJANO, Aníbal (1993). “Raza, etnia y nación en Mariátegui: cuestiones abiertas”, en: Aníbal Quijano et al. José Carlos Mariátegui y Europa. El otro aspecto del descubrimiento. Lima: Amauta, pp. 167-188.

QUIJANO, Aníbal (2000a).“Colonialidad del poder, eurocentrismo y América Latina”, en: Edgardo Lander (comp.), Colonialidad del saber: eurocentrismo y ciencias sociales. Perspectivas latinoamericanas. Buenos Aires, Clacso/Unesco, pp. 201-246.

QUIJANO, Aníbal (2000b). “Colonialidad del poder, globalización y democracia”, en: Tendencias básicas de nuestra época. Caracas, Instituto de Altos Estudios Internacionales Pedro Gual, pp. 21-65.

QUIJANO, Aníbal (2000c). "Colonialidad del poder y clasificación social”, en: Journal of WorldSystems Research, Vol. VI, No. 2, American Sociological Association, pp. 342-386.

QUIJANO, Aníbal (2001). “Colonialidad, poder, cultura y conocimiento en América Latina”, en: Walter Mignolo (comp.), Capitalismo y geopolítica del conocimiento. El eurocentrismo y la filosofía de la liberación en el debate intelectual contemporáneo. Buenos Aires: Signo, pp. 117-131.

QUIJANO, Aníbal (2004).“O'movimento indígena'e as questões pendentes na America Latina”, en: Política externa, vol. 12, № 4, pp. 77-97.

QUIJANO, Aníbal (2007).“Don Quijote y los molinos de viento en América Latina”, en: Investigaciones Sociales, Año X, No. 16, Lima, Universidad Nacional Mayor de San Marcos - Instituto de Investigaciones histórico sociales, pp. 347-368.

QUIJANo, Aníbal (2009). “Des/colonialidad del poder: El horizonte alternativo", en: Pasado y Presente, $\mathrm{N}^{\circ} 21$.

QUIJANo, Aníbal (2010). “Bien vivir" para redistribuir el poder. Los pueblos indígenas y su propuesta alternativa en tiempos de dominación global", en: Oxfam, Pobreza, desigualdady desarrollo en el Perú. Informe anual 2009-2010. 